\title{
Effect of Ethylene Glycol on Structural Integrity at Each Stage of Preantral Follicle Development Post Vitrification of Rat Ovary- Histological Analysis
}

\author{
Nova Anita ${ }^{1,2}$, Abinawanto ${ }^{1 *}$, Ahmad Aulia Jusuf ${ }^{3}$, Anom Bowolaksono ${ }^{1}$, Huriyah Adani Saoemi ${ }^{4}$ \\ ${ }^{1}$ Department of Biology, Faculty of Mathematics and Natural Sciences, Universitas Indonesia, Depok, Indonesia \\ ${ }^{2}$ Cellular and Molecular Mechanism in Biological System Research Group, Department of Biology, Universitas Indonesia, Depok, \\ Indonesia \\ ${ }^{3}$ Department of Histology, Faculty of Medicine, Universitas Indonesia, Jakarta, Indonesia \\ ${ }^{4}$ Master's Programme in Biomedical Sciences, Faculty of Medicine, Universitas Indonesia, Jakarta, Indonesia
}

\section{ARTICLE INFO}

Article history:

Received July 19, 2021

Received in revised form August 25, 2021

Accepted September 23, 2021

\section{KEYWORDS:}

Cryoinjury,

follicle density,

follicle index,

grading method,

preservation

\begin{abstract}
The structure of follicular tissue affects the ability to maintain the structural integrity of follicles against cryoinjury post-vitrification. Histological analysis was conducted on the structural integrity of each stage of preantral follicles postvitrification using $\mathbf{7 . 5 \%}$ and $\mathbf{1 5 . 0 \%}$ doses of ethylene glycol (EG), and ovarian sections with HE staining were observed using an Olympus CX21 microscope connected to Optilab 3.0 lens and Image Raster software. Analysis was conducted on the ovarian cortex in the tracing line area using polygon measure tools to obtain follicle density (follicles $/ \mathrm{mm}^{2}$ ) and follicle index (\%) data. The result showed that the EG group 7.5\% (KP1) increased follicle density compared to the vitrified group $(K K V)$ in primordial $(15.83 \pm 1.77)$ and primary $(22.94 \pm 8.51)$ stages. Meanwhile, KP2 (EG 15\%) was in primordial $(41.92 \pm 6.45)$, primary $(11.69 \pm 1.95)$, secondary $(33.48 \pm 3.63)$, and tertiary (5.93 \pm 0.69$)$ stages. KP1 increased grade 3 follicle index compared to $K K V$ in primary $(27.66 \pm 2.34)$, secondary $(32.41 \pm 6.99)$, and tertiary (25.00 \pm 5.00) stages. Meanwhile, KP2 was in primary (26.87 \pm 6.68$)$ and tertiary (25.00 \pm 5.00$)$ stages. Both doses of $7.5 \%$ and $15.0 \%$ EG were able to maintain structural integrity at certain stages of preantral follicles. Secondary and tertiary follicles are the best stages in maintaining grade 3 follicular integrity with the addition of $7.5 \%$ EG.
\end{abstract}

\section{Introduction}

Follicle preservation through ovarian vitrification technique aims to produce competent oocytes for in vitro culture (Amorim et al. 2003). The follicle is the basic structure and functional unit of the ovary that provides the microenvironment needed for oocyte growth and maturation (Collado-Fernandez et al. 2012). These oocytes were obtained from preantral follicles, which consist of primordial, primary, and secondary follicles, that make up $90 \%$ of the ovarian population (Amorim et al. 2003).

The cryoinjury due to the formation and melting of ice crystals during the cooling and thawing process as well as changes in osmotic pressure during the vitrification causes damage and disrupts the fluidity of the follicular cell membrane (Jang et al. 2017). This damage causes the release of oocyte granulosa cells

\footnotetext{
* Corresponding Author

E-mail Address: abinawanto.ms@sci.ui.ac.id
}

when cultured which will affect oocyte maturation (Kim et al. 2018). Studies on the structure of the preantral follicle of post-vitrified rat ovaries are limited to the number and viability of follicles that are maintained post-vitrification using the EG at a dose of 3.75-15.0\% (Milenkovic et al. 2012; Fathi et al. 2013). Meanwhile, studies on how the integrity of the follicular structure in each preantral follicles is to be maintained with the correct optimal dose are still limited. Therefore, this study is necessary to identify the potential of primordial, primary, secondary, and tertiary follicles which are to be utilized after preservation (Campos et al. 2019).

Ethylene glycol(EG) has a small molecular weight of $62.068 \mathrm{~g} / \mathrm{mol}$ with a lower level of toxicity compared to dimethyl sulfoxide (DMSO) and propanediol (PROH). Furthermore, the disadvantage when dehydrated, it enters the intracellular fluid during the cooling process, and it still forms an incomplete glass layer that triggers cryoinjury and cell damage (Fathi et al. 2013). Therefore, the use of the right type and amount of intracellular cryoprotectant is needed to reduce the potential for cell 
damage during the vitrification. This strategy requires complete information on how to describe the structural integrity of each type of post-vitrified preantral follicle using EG as an intracellular cryoprotectant.

To date, rodents, especially mice, are the only species that undergo a complete in vitro culture process from the primordial stage to offspring (Dole et al. 2008). Furthermore, this study used rat ovary to identify the structural integrity at each stage of the preantral follicle and to obtain the optimum dose of EG that maintains the integrity at each post-vitrified preantral follicle stage. These data are needed as a basis and information input in the development of methods to maintain ovarian function, especially in high economic value, rare animals, and endangered animals whose populations are decreasing due to inbreeding depression caused by climate change (Ledda et al. 2001). Another goal is to maintain ovarian function in cancer patients of reproductive age undergoing chemotherapy, which causes ovarian dysfunction, premature apoptosis, and decreased female reproductive function (Meirow and Nugent 2001).

\section{Materials and Methods}

This research is experimental, using 24 samples of rat (Rattus norvegicus) ovary, which is determined according to the Resource Equation method (Charan and Kantharia 2013). Inclusion criteria: female rats, Sprague-Dawley strain, 7-10 weeks of age, healthy, active, 120-150 g of body weight, obtained from the Indonesian Research Center for Veterinary Sciences, Bogor. Rats were randomly divided into 4 groups, a normal control group without vitrification (KKN), a vitrified control group with $0.9 \% \mathrm{NaCl}(\mathrm{KKV})$, a vitrified treatment group with 7.5\% EG (KP1), a vitrified treatment group with $15 \%$ EG (KP2).

\subsection{Proestrus Phase Identification}

Ovarian isolation was conducted in the proestrus phase by observing vaginal epithelial cytology. Vaginal epithelial isolation procedure refers to the method of Marcondes et al. (2002) and Sjahfirdi et al. (2013). Observation of the vaginal epithelium was conducted using a light microscope with 100x and 400x magnifications by observing the most representative cells. The proestrus phase was characterized by a moderate amount of SNAC $(++)$, a high number of NAC (+++), a small amount of EAC (++), and a few neutrophils (++) (Cora et al. 2015).

\subsection{Euthanasia and Ovarian Isolation}

Euthanasia of experimental animals was conducted using an intraperitoneal injection of a lethal dose of 148 $\mathrm{mg} / \mathrm{kg}$ of ketamine, and this procedure has been approved by The Ethics Committee of the Faculty of Medicine,
Universitas Indonesia-Ciptomangunkusumo Hospital with protocol number 21-05-0531. The ovaries were then cleaned using $0.9 \% \mathrm{NaCl}$ solution and immediately immersed in $10 \%$ formal saline fixation medium (for $\mathrm{KKN}$ ) or $0.9 \% \mathrm{NaCl}, 7.5 \%$, and $15.0 \%$ EG vitrification medium.

\subsection{Vitrification and Thawing}

The vitrification medium consisted of EG 7.5\% and $15.0 \%$. The cryotubes were then exposed to liquid nitrogen vapor for 10 seconds to allow time for the cryoprotectants to penetrate the cells. After that, the cryotubes were immersed into liquid nitrogen at a temperature of $-196^{\circ} \mathrm{C}$ for 48 hours. Then the thawing process was carried out by immersing the cryotube containing the ovaries into a water bath with a temperature of $\pm 37^{\circ} \mathrm{C}$ for 3 minutes (Milenkovic et al. 2012).

\subsection{Preantral Follicle Histological Analysis}

Histological staining processes were conducted using the paraffin method and were stained with Hematoxylin-Eosin (HE) at the Histology Laboratory FMUI (Anita 2004). Tissue sectioning was conducted serially with a thickness of $5 \mu \mathrm{m}$, and a length of $50 \mu \mathrm{m}$ interval between serials (Watermann et al. 2008). Each type of preantral follicle was observed for its structure using a light microscope (Olympus CX21) connected to Optilab 3.0 lens and Image Raster software. Histological analysis, which includes the identification of the integrity structure and the density of the follicles was conducted.

The parameters of intact follicles are:

- The granulosa cells are dense, regular, without vacuolization, and have intact, dense, regular in shape nucleus (Myers et al. 2004)

- The space between the oocyte and the granulosa cells is narrow (Picut et al. 2015)

- The oocytes are round, regular, dense, have the appearance of a nucleolus, and surrounded by an intact zona pellucida (Myers et al. 2004)

While the structure of the atresia follicle has the following criteria:

- The granulosa cells are loose, not dense, irregular, separated from each other, with vacuolization (Picut et al. 2015), and have an irregular shape nucleus (Zhou et al. 2010)

- $\quad$ Enlarged space between oocyte and granulosa cells (Wang et al. 2016)

- The oocytes are not intact, irregular, dense, shrunken (Myers et al. 2004), pyknotic (Wang et al. 2016), with non intact zona pelucida 
The follicular integrity of each preantral stage was evaluated according to the following criteria (Lee et al. 2015):

Primordial/primary follicle:

G1 : Oocytes are deformed, irregular, and pyknotic

G2 : The granulosa cells are not dense, irregular, but the oocyte is round, intact, and dense

G3 : Round follicles with dense and regular granulosa cells, without vacuolization

Secondary/tertiary follicle:

G1 : Irregular follicles, loss of granulosa cells, pyknotic nuclei, and irregular oocytes

G2 : Follicles are not round, granulosa and theca cell between layers are not evenly distributed, loose, irregular but the oocytes are intact, dense, and homogeneous

G3 : Round follicles, granulosa, and theca cells between layers are evenly distributed, oocytes are round, intact, dense, and homogeneous, and the antrum is intact

The characteristics of intact follicles that meet the criteria are in grade 3 (Lee et al. 2015).

Follicle density was analyzed by counting each follicle in the ovarian cortex (number of follicles/cortex area $\left(\mathrm{mm}^{2}\right)$ ) in the tracing line area determined using the polygon measure tool. This technique has been validated and used extensively to estimate cell density in heterogeneous tissues (Courbiere et al. 2005).

\section{Results}

\subsection{Preantral Follicle Density}

Table 1, Figure 1, and the results of the LSD test ( $p \leq 0.05$ ) showed that vitrification caused a decrease in follicle density (follicles $/ \mathrm{mm}^{2}$ ) in all stages of preantral follicles with the highest decrease in the tertiary stage $(0.73 \pm 1.26)$, and the lowest in the primordial $(8.51 \pm 3.09)$ and secondary $(12.54 \pm 4.40)$ stages.

The data also showed that the group with 7.5\% EG dose (KP1) was able to increase follicle density compared to the vitrified group without cryoprotectant (KKV) in the primordial $(15.83 \pm 1.77$ $>8.51 \pm 3.09)$ and primary $(22.94 \pm 8.51>2.41 \pm 1.32)$ stages. Meanwhile, KP2 (EG 15\%) in the primordial $(41.92 \pm 6.45>8.51 \pm 3.09)$, primary $(11.69 \pm 1.95>$ $2.42 \pm 1.32)$ secondary $(33.48 \pm 3.63>12.54 \pm 4.40)$, and tertiary $(5.93 \pm 0.69>0.73 \pm 1.26)$ stages.

TheEG dose of 7.5\% showed that follicle density was not significantly different $(p>0.05)$ with the control group without vitrification (KKN) in the primary $(22.94 \pm 8.51>16.70 \pm 2.43)$ and tertiary $(4.11 \pm 1.67$ $<4.50 \pm 1.83$ ) stages. Meanwhile, the 15\% EG dose showed no significant difference in follicular density ( $p>0.05$ ) with KKN at all stages of preantral follicles; primordial $(41.92 \pm 6.45>37.14 \pm 16.05)$, primary $(11.69 \pm 1.95<16.70 \pm 2.43)$, secondary $(33.48 \pm 3.63<$ $41.47 \pm 6.84)$, and tertiary $(5.93 \pm 0.69>4.50 \pm 1.83)$.

\subsection{Follicle Index}

The comparison of the histological structure of atretic follicles with intact follicles and between grades can be seen in Figure 2 and 3 . The results

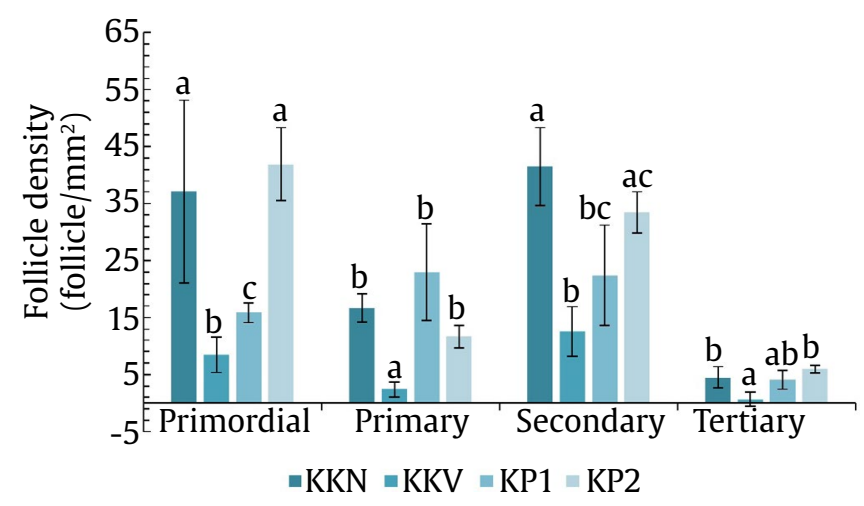

Figure 1. The ovarian follicle density. The bar shows SD; the different letters indicate a significant difference ( $p$ $\leq 0.05)$

Table 1. The ovarian follicle density between groups (follicles $/ \mathrm{mm}^{2}$ )

\begin{tabular}{lllll}
\hline Follicle & KKN & KKV & KP1 & KP2 \\
\hline Primordial & $37.14 \pm 16.05^{\mathrm{a}}$ & $8.51 \pm 3.09^{\mathrm{b}}$ & $15.83 \pm 1.77^{\mathrm{c}}$ & $41.92 \pm 6.45^{\mathrm{a}}$ \\
Primary & $16.70 \pm 2.43^{\mathrm{b}}$ & $2.42 \pm 1.32^{\mathrm{a}}$ & $22.94 \pm 8.51^{\mathrm{b}}$ & $11.69 \pm 1.95^{\mathrm{b}}$ \\
Secondary & $41.47 \pm 6.84^{\mathrm{a}}$ & $12.54 \pm 4.40^{\mathrm{b}}$ & $22.38 \pm 8.82^{\mathrm{bc}}$ & $33.48 \pm 3.63^{\mathrm{ac}}$ \\
Tertiary & $4.50 \pm 1.83^{\mathrm{b}}$ & $0.73 \pm 1.26^{\mathrm{a}}$ & $4.11 \pm 1.67^{\mathrm{ab}}$ & $5.93 \pm 0.69^{\mathrm{b}}$ \\
Total follicles & $99.81 \pm 19.63^{\mathrm{a}}$ & $24.19 \pm 4.87^{\mathrm{b}}$ & $65.26 \pm 9.51^{\mathrm{c}}$ & $93.01 \pm 7.43^{\mathrm{a}}$ \\
\hline
\end{tabular}

Density data are shown as means \pm SD

The different letters indicate a significant difference $(\mathrm{p} \leq 0.05)$ 

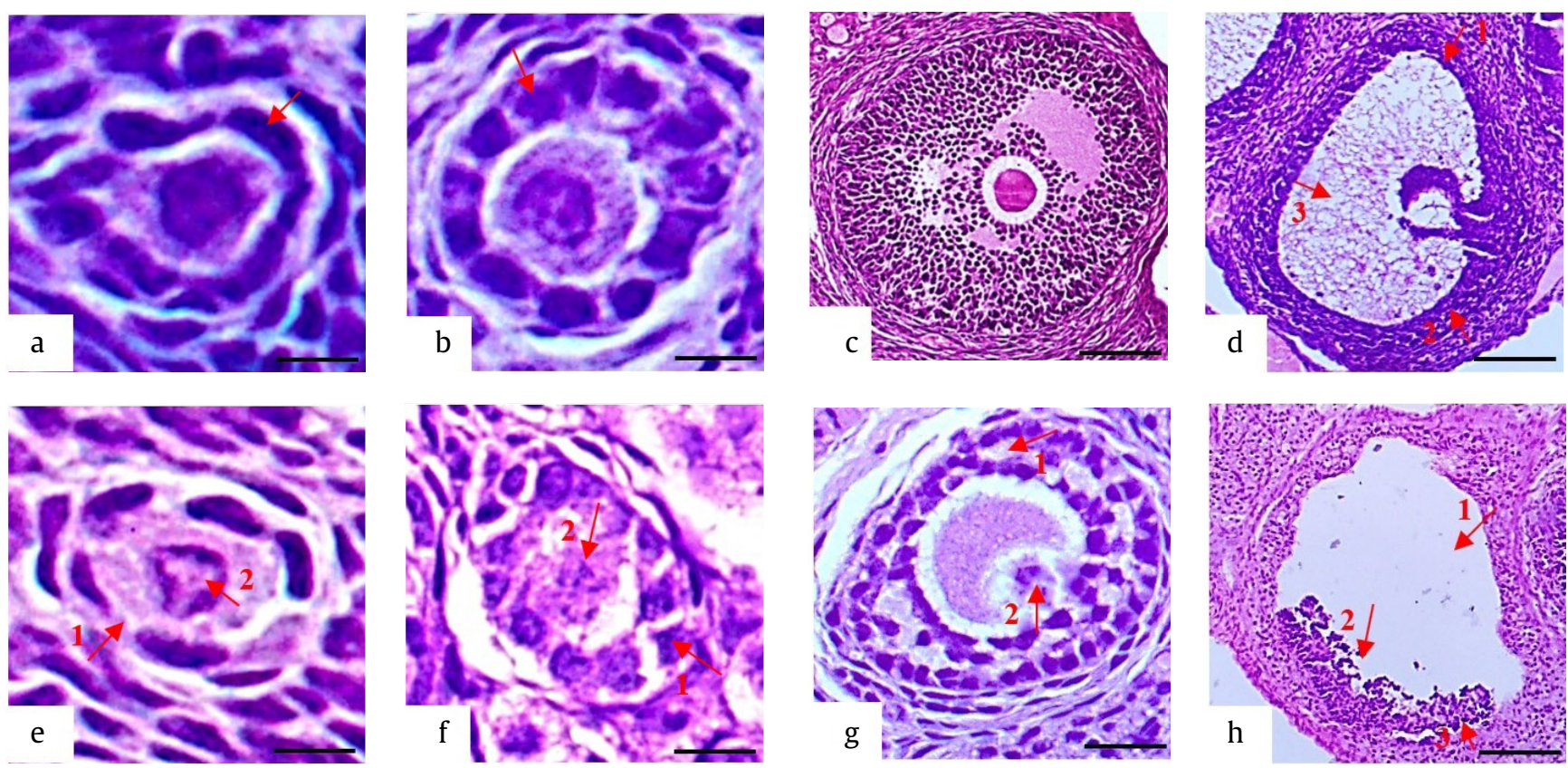

Figure 2. Histological structure of grade 3 intact and atretic preantral follicles. (a) Intact primordial follicle with squamous epithelial cells (red arrow) (400x magnification) (b) intact primary follicle with cuboidal epithelial cells (red arrow) (400x magnification), (c) intact secondary follicle with zona pellucida and intact basement membrane (400x magnification), (d) intact tertiary follicle with dense interlayer granulosa cells (red arrow 1), theca cells (red arrow 2) and antrum cavity clearly visible (red arrow 3) (400x magnification), (e) atretic primordial follicle with vacuolization (red arrow 1), oocyte nucleus fragmentation, and condensation (red arrow 2) (400x magnification), (f) atretic primary follicle with irregular cell arrangement (red arrow 1 ) and atretic oocytes (red arrow 2) (400x magnification), (g) atretic secondary follicle with vacuolization (red arrow 1 ), non-intact oocytes (red arrow 2), non-intact zona pellucida, oocyte nucleus fragmentation, and condensation (400x magnification), (h) atretic tertiary follicle with enlarged antrum cavity (red arrow 1 ), atretic granulosa cells (red arrow 2), nonintact basement membrane (red arrow 3) (400x magnification). (a, e) scale bar $=50 \mu \mathrm{m}$, (b, f) scale bar $=100 \mu \mathrm{m}$, (c, d, g, h) scale bar $=200 \mu \mathrm{m}$

showed that vitrification increased the index of grade 1 follicles which were categorized as atretic follicles in the primordial, primary and tertiary stages. Also, it showed the differences in the ability of follicles to maintain their structural integrity at grade 2 or 3 after the addition of EG, both at a dose of $7.5 \%$ and $15.0 \%$. EG dose of $7.5 \%$ was able to increase the integrity of grade 2 follicles with the highest was in the primordial stage $(47.78 \pm 13.47 \%)$, as well as the integrity of the grade 3 follicles in the primary (27.66 $\pm 2.34 \%)$, secondary $(32.41 \pm 6.99 \%)$ and tertiary (25.00 $\pm 5.00 \%)$ stages. Meanwhile, EG dose of $15 \%$ increased the integrity of grade 2 follicles with the highest was in the primordial stage (50.82 $46.94 \%)$, as well as the integrity of grade 3 follicles in the primary $(26.87 \pm 6.68 \%)$ and tertiary stages $(25.00 \pm 5.00 \%)$ (Table 2 and Figure 4).

\section{Discussion}

The decrease in follicular density at all stages of follicles is thought to be related to plasma membrane damage triggered by changes in osmotic pressure during the vitrification. The plasma membrane is the basic structure for connexin proteins (gap junctions). Gap junctions facilitate communication between granulosa cells that promote proliferation to produce various types of follicles. Ackert et al. (2001) studies showed that the failure of granulosa cell proliferation was caused by the structural damage of the gap junction (Kim and Lee 2021). This factor is thought to affect the decrease in follicle density at all stages of development, which begins with a decrease in the density of the primordial follicle. 


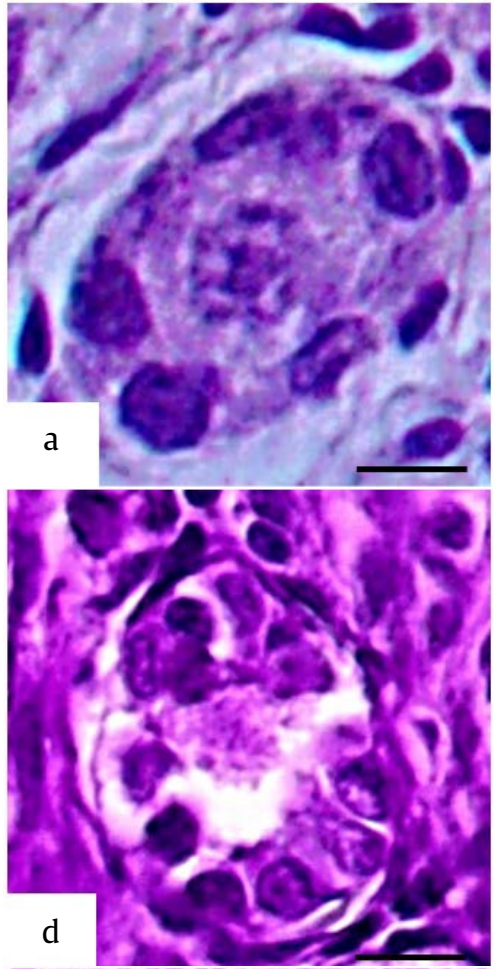

Tiva. Sa $020 \%$ तs

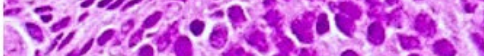

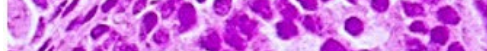
- visar ans ose.

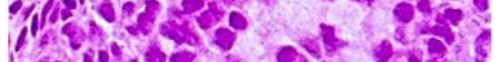

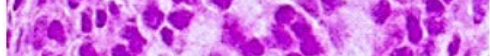

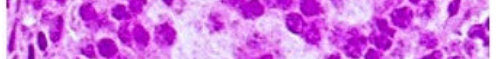

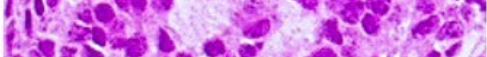

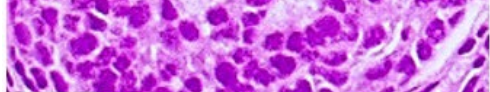
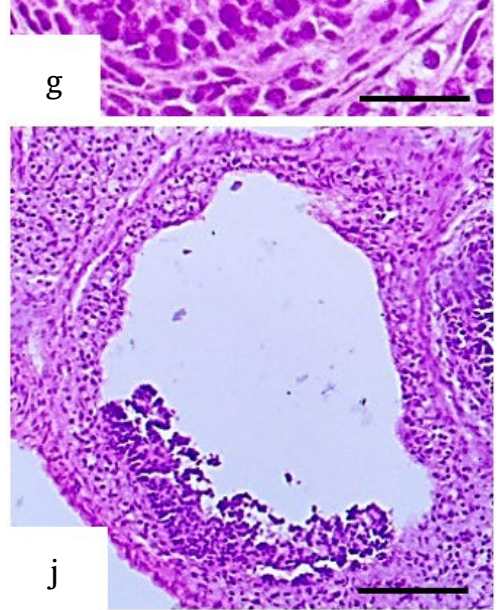
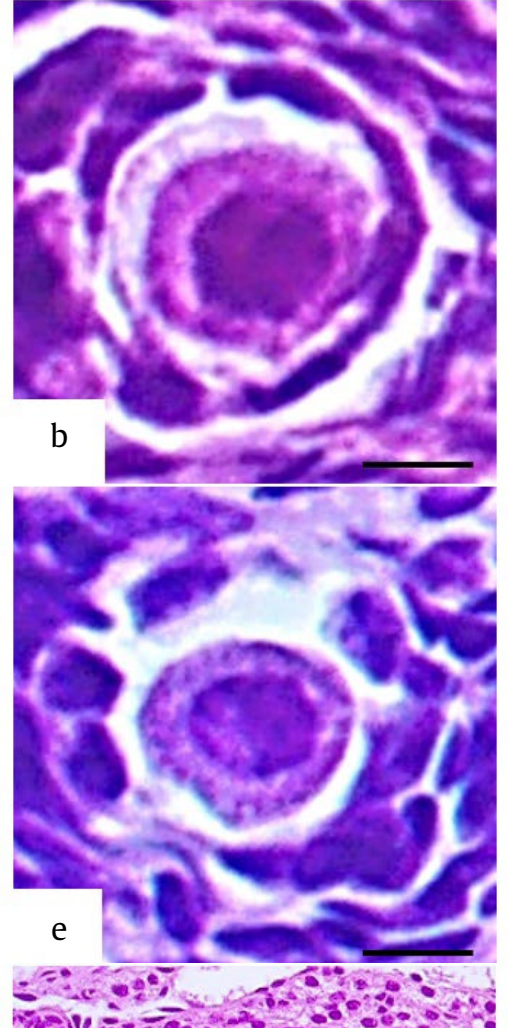

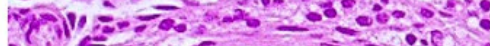

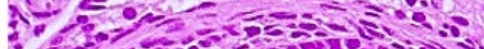

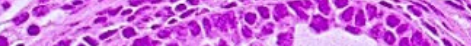

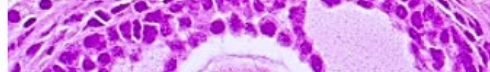
$4.879^{2}$ ?

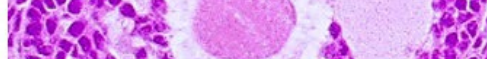

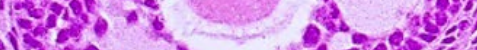

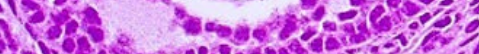

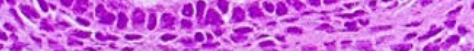

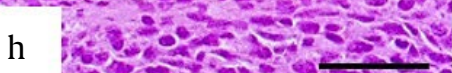

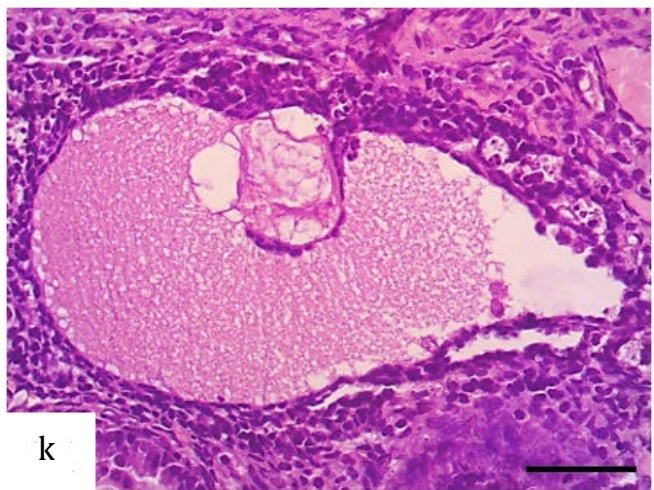

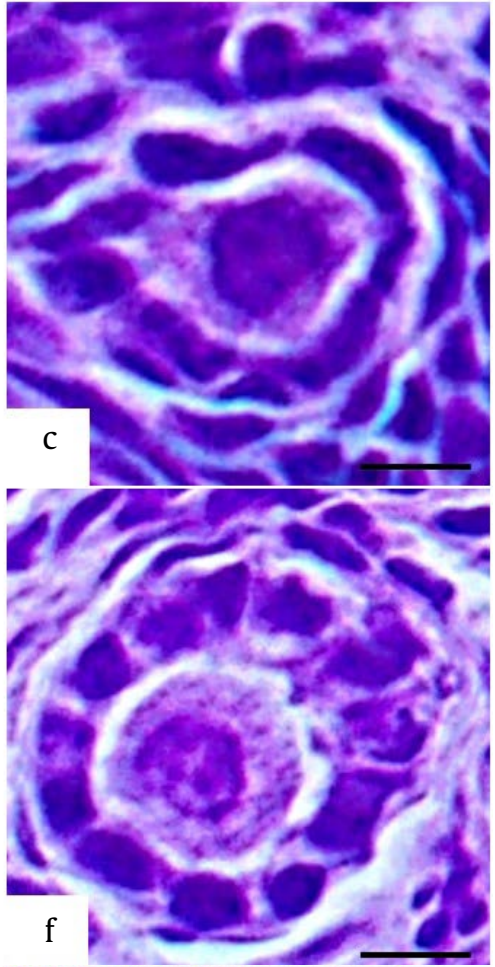
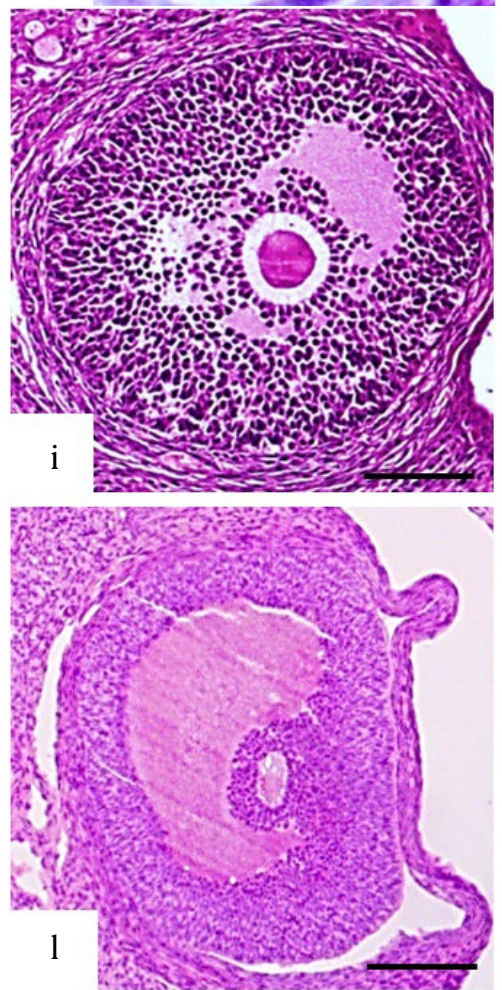

Figure 3. Structural integrity of grade 1, 2, and 3 preantral follicles. (a-c) Grade 1, 2 and 3 primordial follicles, respectively (400x magnification), (d-f) grade 1,2 , and 3 primary follicles, respectively (400x magnification), (g-i) grade 1, 2, and 3 secondary follicles, respectively (400x magnification), (j-1) grade 1,2 , and 3 tertiary follicles, respectively (400x magnification). (a-c) scale bar $=50 \mu \mathrm{m},(\mathrm{d}-\mathrm{f})$ scale bar $=100 \mu \mathrm{m},(\mathrm{g}-\mathrm{l})$ scale bar $=200 \mu \mathrm{m}$ 
Table 2. The percentage of grade 1,2 , and 3 follicle index between groups

\begin{tabular}{clllll}
\hline Grade & Follicle & KKN & KKV & KP1 & KP2 \\
\hline \multirow{2}{*}{1} & Primordial & $47.62 \pm 2.03^{\mathrm{a}}$ & $69.87 \pm 1.38^{\mathrm{b}}$ & $34.44 \pm 5.09^{\mathrm{c}}$ & $42.10 \pm 3.70^{\mathrm{a}}$ \\
& Primary & $27.78 \pm 5.09^{\mathrm{a}}$ & $99.74 \pm 0.35^{\mathrm{b}}$ & $46.64 \pm 3.59^{\mathrm{c}}$ & $39.60 \pm 5.39^{\mathrm{c}}$ \\
& Secondary & $60.37 \pm 2.44^{\mathrm{a}}$ & $56.07 \pm 2.10^{\mathrm{b}}$ & $50.46 \pm 0.61^{\mathrm{c}}$ & $60.87 \pm 1.42^{\mathrm{a}}$ \\
& Tertiary & $5.56 \pm 0.42^{\mathrm{a}}$ & $86.07 \pm 5.19^{\mathrm{b}}$ & $74.94 \pm 3.66^{\mathrm{c}}$ & $68.11 \pm 6.17^{\mathrm{c}}$ \\
\multirow{2}{*}{2} & Primordial & $27.86 \pm 2.58^{\mathrm{a}}$ & $16.98 \pm 2.87^{\mathrm{a}}$ & $47.78 \pm 13.47^{\mathrm{b}}$ & $50.82 \pm 6.94^{\mathrm{b}}$ \\
& Primary & $3.70 \pm 1.70^{\mathrm{a}}$ & $0.09 \pm 0.03^{\mathrm{a}}$ & $25.70 \pm 2.59^{\mathrm{b}}$ & $33.54 \pm 6.37^{\mathrm{c}}$ \\
& Secondary & $5.69 \pm 0.51^{\mathrm{a}}$ & $30.89 \pm 2.38^{\mathrm{b}}$ & $17.13 \pm 4.88^{\mathrm{c}}$ & $24.38 \pm 1.44^{\mathrm{d}}$ \\
& Tertiary & $61.67 \pm 7.64^{\mathrm{b}}$ & $0.05 \pm 0.01^{\mathrm{a}}$ & $0.06 \pm 0.02^{\mathrm{a}}$ & $6.89 \pm 1.02^{\mathrm{c}}$ \\
& Primordial & $24.52 \pm 4.31^{\mathrm{a}}$ & $13.15 \pm 1.95^{\mathrm{bc}}$ & $17.78 \pm 1.92^{\mathrm{ac}}$ & $7.08 \pm 1.23^{\mathrm{b}}$ \\
& Primary & $68.52 \pm 13.98^{\mathrm{a}}$ & $0.17 \pm 0.03^{\mathrm{b}}$ & $27.66 \pm 2.34^{\mathrm{c}}$ & $26.87 \pm 6.68^{\mathrm{c}}$ \\
& Secondary & $33.95 \pm 4.39^{\mathrm{a}}$ & $13.04 \pm 5.86^{\mathrm{b}}$ & $32.41 \pm 6.99^{\mathrm{a}}$ & $14.75 \pm 4.12^{\mathrm{b}}$ \\
& Tertiary & $32.78 \pm 2.55^{\mathrm{a}}$ & $13.89 \pm 3.47^{\mathrm{b}}$ & $25.00 \pm 5.00^{\mathrm{a}}$ & $25.00 \pm 5.00^{\mathrm{a}}$ \\
\hline
\end{tabular}

Grade 1, 2, and 3 follicle index data are shown as means \pm SD

The different letters indicate a significant difference $(\mathrm{p} \leq 0.05)$
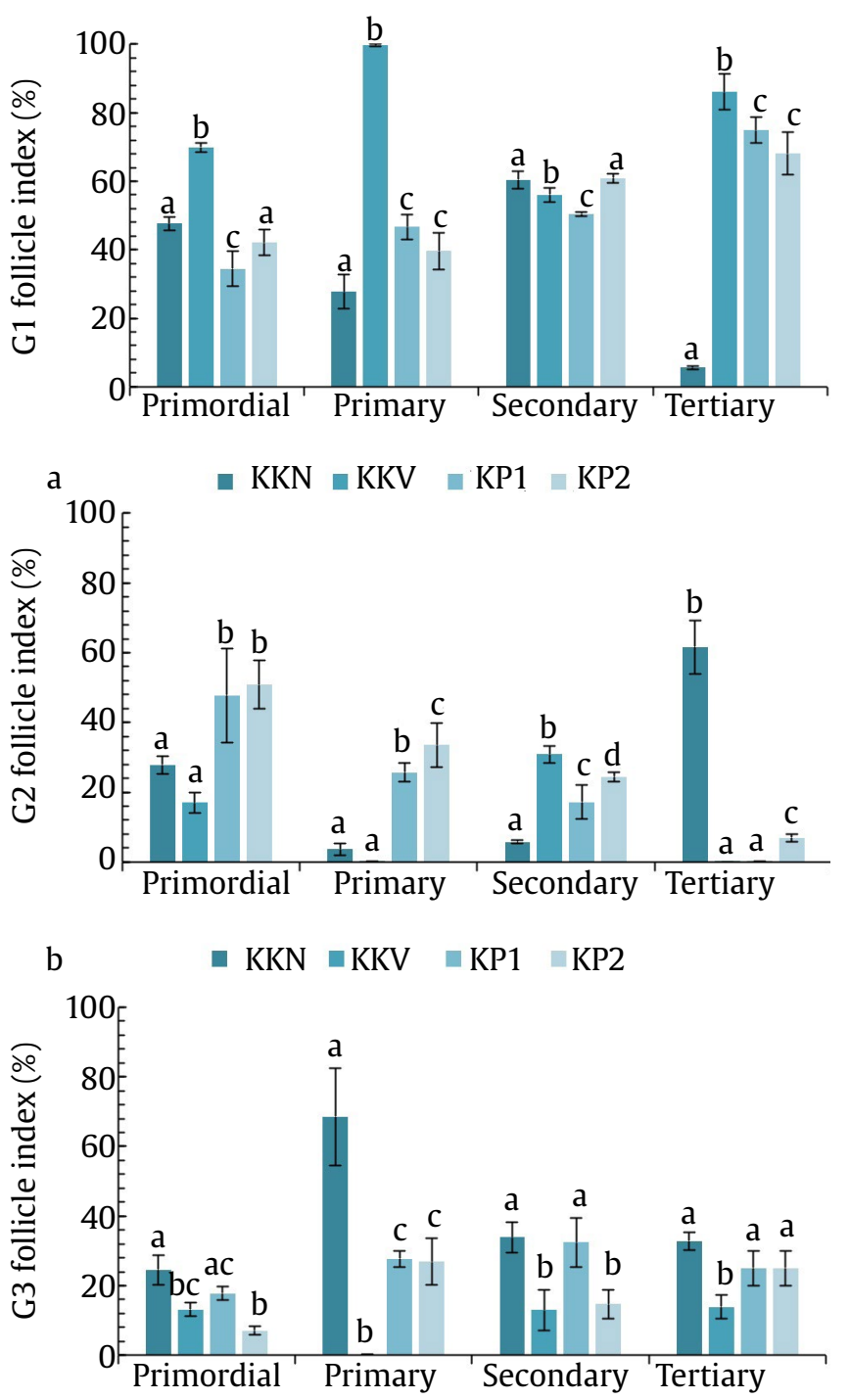

$$
\mathrm{c} \quad \square \mathrm{KKN} \square \mathrm{KKV} \square \mathrm{KP} 1 \square \mathrm{KP} 2
$$

Figure 4 . The percentage of ovarian grade 1,2 , and 3 follicle index. (a) Grade 1 follicle index, (b) grade 2 follicle index, (c) grade 3 follicle index. The bar shows $\mathrm{SD}$; the different letters indicate a significant difference $(\mathrm{p} \leq 0.05)$
However, according to Webb et al. (2004), three phases occur in the folliculogenesis to produce mature oocytes and they include recruitment, selection, and dominance. The recruitment phase begins with the development of primordial follicles derived from the proliferation of "stem cells" which constitute the germinal epithelium of the ovarian cortex, such that the primordial follicles have abundant numbers and better resistance than other types of follicles (Lima et al. 2013). The secondary follicles have a rigid basement membrane layer which serves not only to maintain the compactness of the stratification of the granulosa cell layer but is also protected such that the secondary follicle with this structure is better able to maintain its number from post-vitrification injury (Picut et al. 2015). Furthermore, secondary follicles undergo a selection process to produce tertiary follicles, naturally, that the density of tertiary follicles is the least when compared to other types of preantral follicles. This small amount is thought to decrease further due to the effect of increasing levels of free radicals caused by the increase in extremely cold temperatures during ovarian vitrification which triggers atretic follicles (Aerts and Bols 2010; Afrin et al. 2018).

The addition of EG at a dose of $7.5 \%$ and $15.0 \%$ was able to increase the density of the postvitrification follicle, with an increase that results from the addition of 15.\% dose EG in the primordial, primary, secondary, and tertiary stages. The average intracellular cryoprotectant concentrations that were used were in the range of 5\% to 15\% to allow cells to survive after freezing and thawing process (Kar et al. 2019).

Secondary and tertiary follicles are early antral follicles that undergo the same phase, namely the selection and dominance phase, and also have a relatively similar structure. Therefore, the addition of EG at a dose of $7.5 \%$ or $15.0 \%$ has the same effect 
on the density of the secondary and tertiary follicles, but descriptively, the follicle density which is close to results in the non-vitrified group is KP2 (dose of $15 \%$ ). Thus, the effective dose that increases the density of follicles is a dose of $15 \%$.

The results showed that the grade 1 index which was categorized as atretic follicle had the highest value in almost all stages of follicles in the vitrified group without the addition of EG, except for secondary follicles. This proves that vitrification causes a cryoinjury due to the formation and melting of ice crystals in the cooling and thawing process, which causes damage and disruption of the fluidity of the cell membrane, and affects the integrity of the cell structure (Jang et al. 2017). Secondary follicles have a stratification of the granulosa cell layer and differentiation of this layer into a special layer, theca cells, that have an affinity for local growth factors and gonadotropins. Therefore, these structures are thought to strengthen the resistance of secondary follicles to post-vitrification cryoinjury (Heiligentag and Eichenlaub-Ritter 2018).

Studies have also shown that the earlier the follicle development stage, the better the ability to maintain its structural integrity. The primordial and primary follicles had the best resistance in grade 2 compared to secondary and tertiary follicles, both with the addition of EG at a dose of $7.5 \%$ or $15.0 \%$. This is due to differences in the number and structure of organelles and metabolic activities. Whereas in growing follicles or early antral follicles, the oocyte is actively synthesizing protein and RNA (Hyttel et al. 1997). Follicles at this stage are more sensitive to an environment that is poor in nutrients and oxygen (Thompson et al. 2015). As a result, the process of cell degeneration will take place more quickly.

The results also showed that EG had a toxic effect, which increased with concentration. Furthermore, EG 7.5\% was able to increase the grade 2 follicle index at the primordial and primary stages, due to the maximum penetration capacity of EG through a layer of granulosa cells. However, at the same time, the maximum effect of the toxicity of EG which also triggers cell necrosis, such that with the addition of $15 \%$ EG dose, the primordial grade 3 follicle index was decreased. The more complex structure that constitutes the follicular structure at that stage causes a decrease in the maximum capacity of EG penetration into the intracellular space. On the other hand, the maximum toxicity effect was avoided thereby reducing the number of necrotic cells.

Primordial, primary and tertiary stage follicles are stages of preantral follicles that maintains their structural integrity, both in grade 2 and 3, and this shows the potential of these follicles to be used after the preservation process. There is a positive correlation between follicle density and grade 2 and 3 indexes, especially at the secondary follicle stage. Meanwhile, tertiary follicles have the lowest density but have the best ability to maintain structural integrity post-vitrification.

The addition of EG, both $7.5 \%$, and $15.0 \%$, was able to increase the density of follicles post-vitrification. The optimum dose that can increase the density of follicles at all stages of preantral follicles is a dose of $15 \%$. These results showed the different abilities of each follicle stage in maintaining its structural integrity post-vitrification. The addition of a dose of $7.5 \%$ was better able to maintain the grade 2 follicle index at the primordial and primary stages, while the grade 3 follicle index was at the secondary and tertiary stages.

\section{Acknowledgements}

This study was funded by a Doctoral Dissertation Research Grant year 2021 from the Directorate General of Research Enhancement and Development, Ministry of Research Technology and Higher Education. The authors are grateful to the Head of the Department and lab assistants of Biology and Histology Department Universitas Indonesia that supported this study.

\section{References}

Ackert CL et al. 2001. Intercellular communication via connexin43 gap junctions is required for ovarian folliculogenesis in the mouse. Dev Biol 233:258-270. DOI:10.1006/dbio.2001.0216

Aerts JMJ, Bols PEJ. 2010. Ovarian follicular dynamics: a review with emphasis on the bovine species. Part I: Folliculogenesis and pre-antral follicle development. Reprod. Domest Anim 45:171-179. DOI:10.1111/j.14390531.2008.01302.x

Afrin S et al. 2018. Protective effects of Manuka honey on LPStreated RAW 264.7 macrophages. Part 1: Enhancement of cellular viability, regulation of cellular apoptosis and improvement of mitochondrial functionality. Food Chem Toxicol 121:203-213. DOI:10.1016/j. fct.2018.09.001

Amorim CA et al. 2003. Cryopreservation of oocytes from pre-antral follicles. Hum Reprod Update 9:119-129. DOI:10.1093/humupd/dmg014

Anita N. 2004. Perubahan Sebaran Stadia Ephitel Seminiferus, Penurunan jumlah sel-sel spermatogenik dan Kadar Hormon Testosteron Total Mencit (Musmusculus L) galur DDY yang Diberi Asap Rokok kretek. Jakarta: Fakultas Kedokteran Universitas Indonesia.

Campos LB et al. 2019. Advances and challenges of using ovarian preantral follicles to develop biobanks of wild mammals. Biopreserv Biobank 17:334-341.DOI:10.1089/ bio.2018.0130 
Charan J, Kantharia N. 2013. How to calculate sample size in animal studies? JPharmacol Pharmacother 4:303-306. DOI:10.4103/0976-500X.119726

Collado-Fernandez E et al. 2012. Metabolism throughout follicle and oocyte development in mammals. Int J Dev Biol 56:799-808. DOI:10.1387/ijdb.120140ec

Cora MC et al. 2015. Vaginal cytology of the laboratory rat and mouse: review and criteria for the staging of the estrous cycle using stained vaginal smears. Toxicol Pathol 43:776-793.DOI:10.1177/0192623315570339

Courbiere B et al. 2005. Follicular viability and histological assessment after cryopreservation of whole sheep ovaries with vascular pedicle by vitrification. Fertil Steril 84:1065-1071. DOI:10.1016/j.fertnstert.2005.03.079

Dole G et al. 2008. Glial-derived neurotrophic factor promotes ovarian primordial follicle development and cell-cell interactions during folliculogenesis. Reproduction 135:671-682. DOI:10.1530/REP-07-0405.Glial-derived

Fathi $\mathrm{R}$ et al. 2013. Effects of different cryoprotectant combinations on primordial follicle survivability and apoptosis incidence after vitrification of whole rat ovary. Cryo-Letters 34:228-238.

Heiligentag M, Eichenlaub-Ritter U. 2018. Preantral follicle culture and oocyte quality. Reprod Fertil Dev 30:18-43. DOI:10.1071/RD17411

Hyttel P et al. 1997. Oocyte growth, capacitation and final maturation in cattle. Theriogenology 47:23-32.

Jang TH et al. 2017. Cryopreservation and its clinical applications. Integr Med Res 6:12-18. DOI:10.1016/j. imr.2016.12.001

Kar M et al. 2019. Current Developments in Excipient Science: Implication of Quantitative Selection of Each Excipient in Product Development. In: Basic Fundamentals of Drug Delivery. London: Academic Press. pp. 29-83.

Kim EJ et al. 2018. Comparison of follicle isolation methods for mouse ovarian follicle culture In Vitro. Reprod Sci 25:1270-1278. DOI:10.1177/1933719117737851

Kim SS, Lee JR. 2021. Ovarian cryopreservation and transplantation. In: Fertil Preserv. Cambridge: Cambridge University Press. pp. 243-259.

Ledda S et al. 2001. Oocyte cryopreservation and ovarian tissue banking. Theriogenology 55:1359-1371. DOI:10.1016/ S0093-691X(01)00487-3

Lee JR et al. 2015. Effect of antifreeze protein on mouse ovarian tissue cryopreservation and transplantation. Yonsei Med J 56:778-784. DOI:10.3349/ymj.2015.56.3.778
Lima GL et al. 2013. Morphological characterization of the ovarian preantral follicle population of collared peccaries (Tayassu tajacu Linnaeus 1758). J Vet Med Ser C Anat Histol Embryol 42:304-311. DOI:10.1111/ ahe.12021

Marcondes FK et al. 2002. Determination of the estrous cycle phases of rats: some helpful considerations. Brazilian J Biol 62:609-614. DOI:10.1590/S151969842002000400008

Meirow D, Nugent D. 2001. The effects of radiotherapy and chemotherapy on female reproduction. Hum Reprod Update 7:535-543. DOI10.1093/humupd/7.6.535

Milenkovic $M$ et al. 2012. Viability and function of the cryopreserved whole rat ovary: comparison between slow-freezing and vitrification. Fertil Steril 97:11761182. DOI:10.1016/j.fertnstert.2012.01.123

Myers $M$ et al. 2004. Methods for quantifying follicular numbers within the mouse ovary. Reproduction 127:569-580. DOI:10.1530/rep.1.00095

Picut CA et al. 2015. Postnatal ovary development in the rat: morphologic study and correlation of morphology to neuroendocrine parameters. Toxicol Pathol 43:343353. DOI:10.1177/0192623314544380

Sjahfirdi L et al. 2013. Pemeriksaan profil hormon progesteron selama siklus estrus tikus (Rattus norvegicus) betina menggunakan perangkat inframerah.Jurnal Kedokteran Hewan 7:32-36.

Thompson JG et al. 2015. The ovarian antral follicle: Living on the edge of hypoxia or not? Biol Reprod 92:1-6. DOI:10.1095/biolreprod.115.128660

Wang TR et al. 2016. Human single follicle growth in vitro from cryopreserved ovarian tissue after slow freezing or vitrification. Hum Reprod 31:763-773. DOI:10.1093/ humrep/dew005

Watermann B et al. 2008. Histological alterations in ovaries of pubertal female rats induced by triphenyltin. Exp Toxicol Pathol 60:313-321. DOI:10.1016/j.etp.2008.03.009

Webb $\mathrm{R}$ et al. 2004. Control of follicular growth: local interactions and nutritional influences. I Anim Sci 82:2299-2302. DOI:10.2527/2004.8213

Zhou XH et al. 2010. Cryopreservation of human ovarian tissue: comparison of novel direct cover vitrification and conventional vitrification. Cryobiology 60:101-105. DOI:10.1016/j.cryobiol.2009.02.006 